\title{
Corpus e géneros textuais nas práticas de divulgação de ciência ou as novas hierarquias na construção do conhecimento ${ }^{1}$
}

\author{
Matilde Gonçalves* \& Miguel Magalhães** \\ *Universidade NOVA de Lisboa, ** CLUNL, FCT, NOVA, CLUNL
}

\begin{abstract}
:
This paper, as result from the research project Scientific Literacy Promotion, funded by the Calouste Gulbenkian Foundation, shows, in a first moment, the heterogeneity of the textual formats that participate in the dissemination of science, widespread by the media in Portugal, starting from the analysis of the relations between corpus, genres and texts. In a second moment, the textual support, in particular the evolution from print to digital, led to a discussion of the linguistic and textual implications of this development, as well as the implications of the new hierarchies of knowledge construction.
\end{abstract}

Keywords: texts, science communication, genres, corpus; digital practices

Palavras-chave: textos, divulgação de ciência, géneros, corpus, práticas digitais

\section{Introdução}

O trabalho, que aqui se apresenta, é parte integrante de um projeto de investigação intitulado Promoção da Literacia Científica, financiado pela Fundação Calouste Gulbenkian, no âmbito do Programa de Investigação nos domínios da Língua e Cultura portuguesas (2016-2017). Com vista à criação de estratégias de intervenção didática para promover a literacia científica de alunos de diferentes ciclos de escolaridade, constituiu-se um corpus de duas centenas de textos que circularam nos média nacionais (4 jornais diários, 2 jornais semanais, 3 revistas mensais), entre maio e junho de 2016, em suporte impresso e em suporte digital. O estudo do corpus incidiu especificamente na análise de textos utilizados na divulgação científica na imprensa portuguesa ${ }^{2}$. Pela análise dos textos do corpus, destacaram-se três problemáticas constitutivas dos objetivos do presente trabalho: 1) Partindo dos textos recolhidos cujo objetivo comum é divulgar ciência, questionar-se-á a natureza genológica (Jorge, 2014) desses textos, quer a partir da etiqueta genérica dada pela imprensa "notícia", "entrevista", entre outras, bem como pela ausência dessa etiquetagem genológica, quer a partir dos recursos semiotizados, em particular os marcadores de género autorreferências (Coutinho \& Miranda, 2009); 2) As flutuações existentes ao nível da organização do conteúdo temático das secções jornalísticas, das tags e do corpo do texto serão destacadas, o que possibilitará discutir as fronteiras (ténues) entre os temas e as práticas de linguagem, em particular a ciência, a saúde, a economia e a tecnologia"; 3) Questionar-se-á as novas relações que se tecem no seio dos textos digitais e as implicações na construção do conhecimento.

Para tal, iniciar-se-á com um breve enquadramento sobre os géneros de texto, seguido do processo e metodologia da constituição e organização do corpus do projeto de investigação, continuar-se-á com uma apresentação sumária de alguns dos textos do corpus, bem como uma discussão relativa à evolução dos meios de circulação dos textos, terminando com as novas hierarquias do conhecimento.

\footnotetext{
${ }^{1} \mathrm{O}$ presente trabalho é financiado por fundos nacionais portugueses, através da FCT - Fundação para a Ciência e Tecnologia, como parte do projeto do Centro de Linguística da Universidade NOVA de Lisboa - UID/LIN/03213/2019 e da bolsa de investigação de Miguel Magalhães, PD/BD/142789/2018, ao abrigo do Programa de Doutoramento FCT "KRUse - Knowledge, Representation \& Use", bem como pela Fundação Calouste Gulbenkian no âmbito do Programa de Investigação nos domínios da Língua e Cultura Portuguesas, PGLCP44.

${ }^{2}$ Para mais informações, veja-se Gonçalves \& Jorge (org) (2018) e o sítio do projeto: www.literaciacientifica.pt
} 


\section{Os géneros sociais: entre o social e a linguística}

$\mathrm{O}$ (re)conhecimento da noção de género deve muito aos trabalhos do Círculo de Bakhtine, em particular à obra Estética da Criação Verbal (1984). No presente estudo, sustentar-nos-emos da proposta de um autor, próximo de Bakthine, V.N. Volochinov ${ }^{3}$, o qual contribuiu para o desenvolvimento dos géneros e, em particular, a ideia de que os géneros influem na organização textual e linguística : "chacun des types de communication sociale [...] organise, construit et achève, de façon spécifique, la forme grammaticale et stylistique de l'énoncé ainsi que la structure du type dont il relève : nous la désignerons désormais sous le terme de genre »(Volochinov, 1929/1977: 289-290). É nesta influência do género sobre as unidades linguísticas que se recupera o programa metodológico descendente, com a proposta de estudar primeiro as atividades sociais, a seguir os géneros ou "atos de fala" e finalmente as "estruturas linguísticas" (Volochinov 1929/1977:137-139):

[...] l'ordre méthodologique pour l'étude de la langue doit être le suivant :

1. Les formes et les types d'interaction verbale en liaison avec les conditions concrètes où celles-ci se réalisent.

2. Les formes des énonciations distinctes, des actes de parole isolés, en liaison étroite avec l'interaction dont ils constituent les éléments, c'est-à-dire les catégories d'actes de parole dans la vie et dans la création idéologique qui se prêtent à une détermination par l'interaction verbale.

3. A partir de là, l'examen des formes de la langue dans leur interprétation linguistique habituelle. Volochinov ([1929] 1977: 137)

Este programa metodológico foi retomado por diversos autores, tais como Adam (1990), Bronckart (1997), (2008), bem como Rastier (2001). Ainda no que toca à noção de género, importa igualmente notar que a noção em causa convoca duas questões fundamentais: a primeira relaciona o género com o conjunto das atividades de linguagem, isto é, as atividades comunicativas que irão influenciar a escolha do género; a segunda diz respeito à produção textual, aquando da evidenciação dos elementos linguísticos e textuais que relevam do género convocado, tendo em conta que o texto corresponde à materialização empírica do género. Assim, enquanto a primeira questão reenvia à relação entre atividades de linguagem e género, a segunda relaciona-se com a estabilidade do género. Como sublinhado quer por Adam (1997: 670), quer por Rastier (2001 :299), o género não pertence a um domínio estritamente linguístico, sendo um produto social, possui uma dimensão cultural e histórica e simultaneamente, sendo uma referência a nível da textualização, orienta a organização e a interpretação dos textos. Além disso, a natureza dos géneros é fundamentalmente sociocomunicativa, estes correspondem a dispositivos maleáveis, dinâmicos que se transformam e evoluem em função do tempo, do espaço e do uso realizado pelos agentes textuais. Os géneros surgem em função das necessidades comunicativas e das atividades sociais - substrato da morfogénese genológica ou da vida dos géneros (Gonçalves, 2011).

\section{Constituição e organização do corpus}

Para a constituição do corpus recolheram-se textos em jornais e revistas em língua portuguesa, oriundos de três jornais diários (Público, Jornal de Notícias, Diário de Notícias), de dois jornais semanários (Sol, Expresso) e de três revistas mensais (Super Interessante, Quero Saber, National Geographic Portugal). As recolhas, feitas entre maio e junho de 2016, incluíram dois suportes de circulação (digital e impresso), tendo o

\footnotetext{
${ }^{3}$ A publicação de duas obras - a tradução de Marxismo e Filosofia da linguagem por Patrick Sériot e Inna Tylkowski-Ageeva, publicado em 2010 pelas edições Lambert-Lucas (Limoges), e a de Jean-Paul Bronckart \& Cristian Bota (2011), Bakhtine démasqué. Histoire d'un menteur, d'une escroquerie et d'un délire collectif, publicado em 2011 pela Librairie Droz (Genève) puseram em causa a autoria de certos trabalhos de M. Bakhtine. Este aspeto não será discutido no presente contributo.
} 
digital dois acessos (pago e gratuito). Posteriormente, as recolhas feitas em suporte papel foram digitalizadas e identificadas com uma cota alfanumérica que identifica o suporte original do documento.

No que concerne aos critérios de seleção, importa mencionar a recolha de todos os documentos sob a etiqueta "ciência", incluindo títulos de secção, palavras-chaves (tags) ou palavras-chave com hiperligações (hashtags). A necessidade de incluir palavras-chave e palavras-chave com hiperligações prendeu-se com a adoção de novos formatos digitais e a sua adaptação à tecnologia móvel e às redes sociais onde estão presentes. Depois de recolhido, digitalizado e organizado, o corpus foi disponibilizado no sítio do projeto da Promoção da Literacia Científica em www.literaciacientifica.pt/corpus.

A organização do corpus efetuou-se em função dos domínios científicos e tendo em conta que a divisão entre as diversas áreas científicas é cada vez mais difusa (privilegiando-se a interdisciplinaridade), foi elaborada uma lista de domínios considerados claros para o utilizador, partindo de Library of Congress Classification ${ }^{4}$. Assim, os domínios científicos que constam na lista de pesquisa são os seguintes: Física, Química, Matemática, Medicina, Tecnologia /Engenharia, Antropologia, Sociologia, História, Psicologia, Linguística, Literatura, Filosofia, Zoologia, Botânica, Biologia, Ecologia /Ambiente, Astronomia. Uma vez que não foram encontrados textos para todos os domínios, considerou-se fulcral projetar a lista em questão para acomodar recolhas futuras.

\section{Corpus da Literacia científica: géneros e textos}

A comunicação social atua de modo indubitavelmente relevante na divulgação de ciência, quer no meio impresso, oral ou digital, quer por formatos textuais. Estes últimos subdividem-se em dois grandes grupos, que convivem pacificamente na esfera jornalística: os formatos estabilizados - designados no âmbito da linguística do texto e do discurso como géneros de textos (Adam, 2008, Bronckart, 1997/1999, Coutinho, 2003, Coutinho \& Miranda, 2009) - e os formatos que ainda não se encontram estabilizados (Gonçalves et al., 2018). Os primeiros, os géneros, são facilmente reconhecíveis e identificáveis por terem uma configuração estável e de reconhecimento fácil por parte do leitor - é o caso da notícia, da reportagem ou da entrevista - e apresentam marcas específicas a nível contextual (referentes ao contexto de produção) e textual (associadas à estrutura e aos mecanismos enunciativos, por exemplo). Necessários à realização das ações comunicativas, os formatos textuais estabilizados, são caracterizáveis como espécie de "reservatório de modelos de referência" (Bronckart, 2004) a partir dos quais qualquer produtor realiza as suas ações de linguagem, isto é, os textos.

Com o intuito de divulgar ciência e adotando o formato da reportagem, o Texto 1 exemplifica isso mesmo.

\footnotetext{
${ }^{4}$ https://www.loc.gov/catdir/cpso/lcc.html
} 


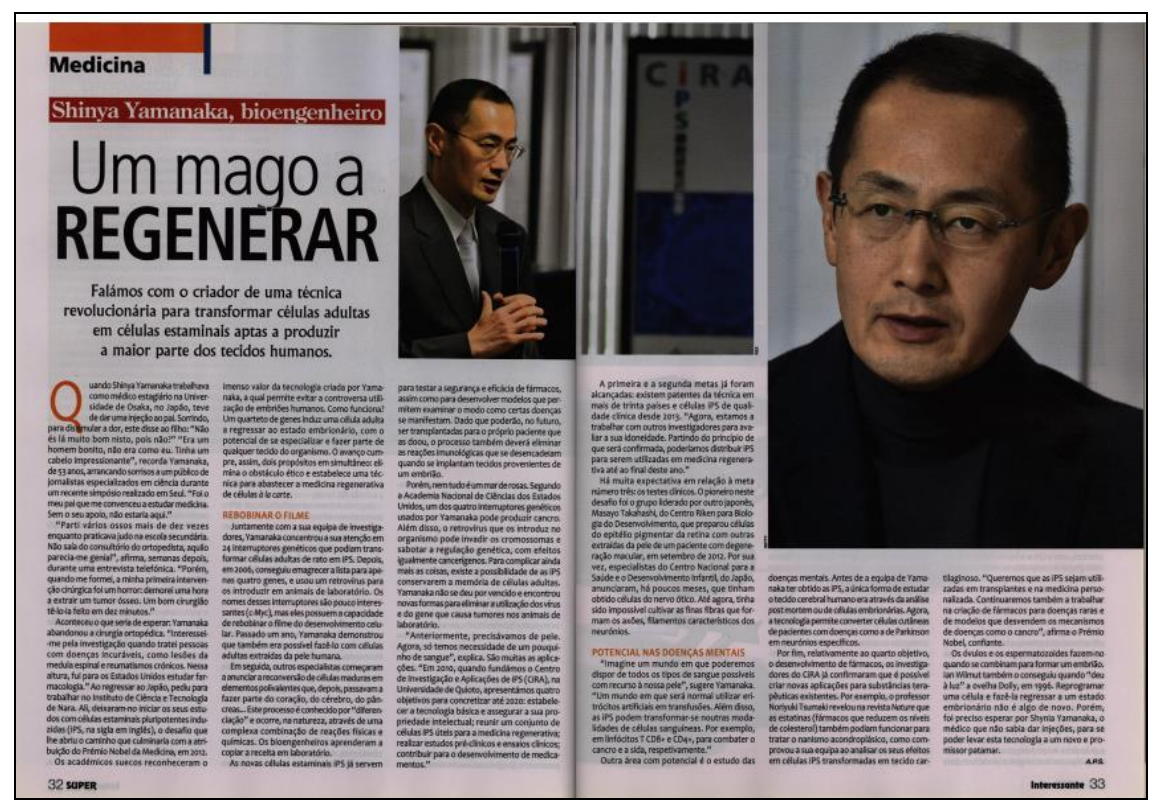

Texto 1. "Um mago a regenerar"

http://www.literaciacientifica.pt/pdf_files/SI_0010_P_179.pdf

Este texto intitulado "Um mago a regenerar", publicado na revista Super Interessante, apresenta traços e marcadores genéricos (Coutinho \& Miranda, 2009) que tornam possível a sua categorização como reportagem; a nível estrutural, essa classificação é possível pela presença de um título, assinalado graficamente por um tamanho de letra diferenciado do corpo do texto, seguido de uma breve síntese, na qual é apresentada a descoberta científica e do corpo da reportagem, disposto por colunas, característica do suporte impresso (a reportagem ou outro género da atividade jornalística, em suporte digital, surgem dispostos numa coluna única). A articulação entre as diversas partes do texto circunscreve o reconhecimento do género reportagem, a saber: o título principal a encabeçar o texto (com o objetivo de chamar a atenção do leitor, quer pelo conteúdo, quer pelo tamanho da letra), a identificação do médico e bioengenheiro (tema central do texto), a temática na qual a reportagem se insere ("Medicina") e pelo corpo da reportagem. Para além disso, estabelece-se uma relação de complementaridade semântica e temática entre a fotografia e as diversas denominações atribuídas "bioengenheiro | mago | criador de uma técnica revolucionária". Composicionalmente, a reportagem é constituída por blocos textuais diferenciados pelo tamanho da letra e pelas formas de destaque e pela explicitação de elementos paratextuais (título e número de página da revista). Este género caracteriza-se, ainda, por um determinado grau de subjetividade (veja-se a escolha de "mago" para caracterizar o cientista) e de implicação por parte do produtor textual (jornalista), com o recurso à primeira pessoa do plural "falámos".

O texto 2 releva do género entrevista, tal como indicado pelo marcador autoreferencial (Coutinho \& Miranda, 2009) "Entrevista", situado no canto superior esquerdo. 


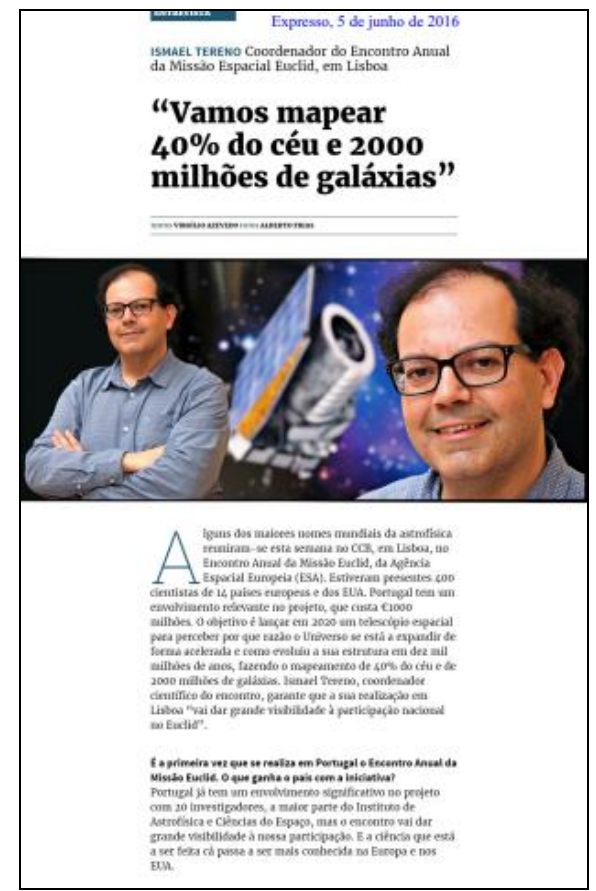

Texto 2. "Vamos mapear 40\% do céu e 2000 milhões de galáxias" http://www.literaciacientifica.pt/pdf_files/EXP_0016_P_129.pdf

Neste texto, o título é constituído por uma citação apresentada com aspas evidenciando a divulgação de um acontecimento científico da área da astronomia realizada pelo cientista, com recurso à $1 .^{a}$ pessoa do singular. Para além do título, a relação entre a parte não verbal - a fotografia do cientista, responsável pela produção do enunciado constitutivo do título - e a parte verbal - a etiqueta genérica "entrevista", o título, a identificação do cientista entrevistado, do jornalista e do fotógrafo - funciona de forma articulada para criar o a semiotização do conteúdo temático, a saber o mapeamento do céu e das galaxias. A configuração da mancha gráfica é formada por um bloco textual introdutório e blocos textuais constituídos por perguntas a negrito e respostas, facto que confirma a composicionalidade da entrevista.

O texto 3, como a seguir se apresenta, conforma características identificadoras da sua natureza genológica, a saber a notícia. 


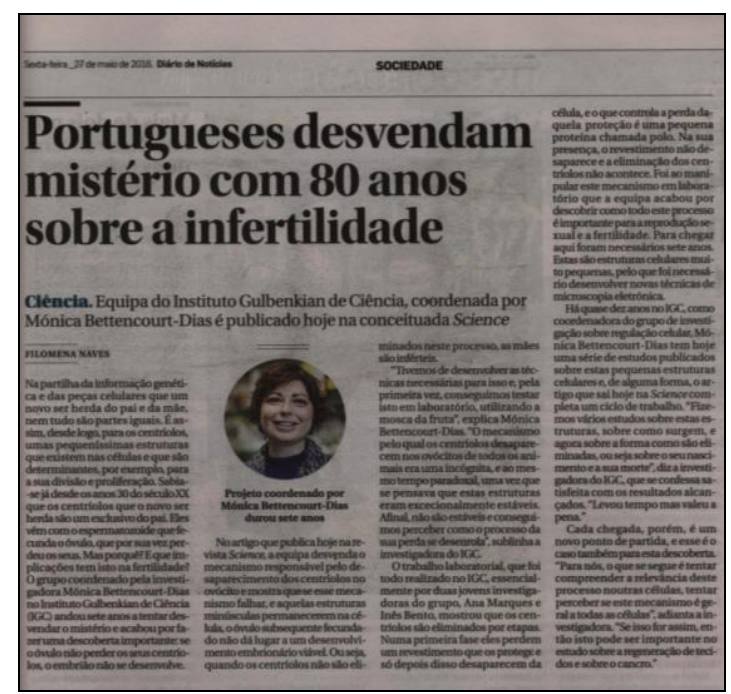

Texto 3. "Portugueses desvendam mistério com 80 anos sobre a infertilidade" http://www.literaciacientifica.pt/pdf_files/DN_0001_P_4.pdf

Composicionalmente, a notícia destaca-se pela presença de um título e de um lead, pela disposição em colunas, bem como pelos diversos modos de relação entre essas diversas partes, a saber: o título principal e o lead, o qual vem complementar o título e sintetizar alguns dos aspetos mais relevantes da notícia (quem, quando, onde, o quê, como), a identificação da jornalista, a secção/temática "Ciência" e o corpo do texto da notícia. Para além disso, estabelece-se entre a imagem e o texto uma relação de complementaridade (fotografia da cientista, que se relaciona diretamente com o conteúdo temático enunciado no lead "Equipa do Instituto de Ciência da Gulbenkian, coordenada por Mónica Bettencourt-Dias é publicada hoje na conceituada Science" [sic]). A identificação do texto como notícia é garantida ainda pela formatação gráfica (blocos textuais diferenciados pelo tamanho da letra e pelas formas de destaque) e pela explicitação de elementos paratextuais (título e número de página do jornal, data de publicação, identificação da secção, nome do jornalista). Ao longo da notícia, o foco incide fundamentalmente no quem (investigadores, cientistas) e no quê (desaparecimento dos centríolos e sua implicação na infertilidade). A presença de léxico de especialidade, acessível ao leitor não especializado, remete desde logo para a intenção comunicativa do texto: noticiar e divulgar uma descoberta científica.

Se nos três textos apresentados anteriormente é possível determinar a natureza genológica, quer pelo marcador autorreferencial, como é o caso da entrevista, quer por marcadores genéricos composicionais (no que concerne à reportagem e à notícia), ou ainda por marcadores enunciativos, a título de exemplo as marcas de implicação do produtor textual, como se observou na reportagem, existem textos utilizados para divulgar ciência configurados com base em formatos não totalmente estabilizados, isto é não apresentando um formato facilmente reconhecível e que, pelo contrário, são detentores de características que tornam a categorização/classificação genológica mais desafiante, como se observa no texto 4 . 


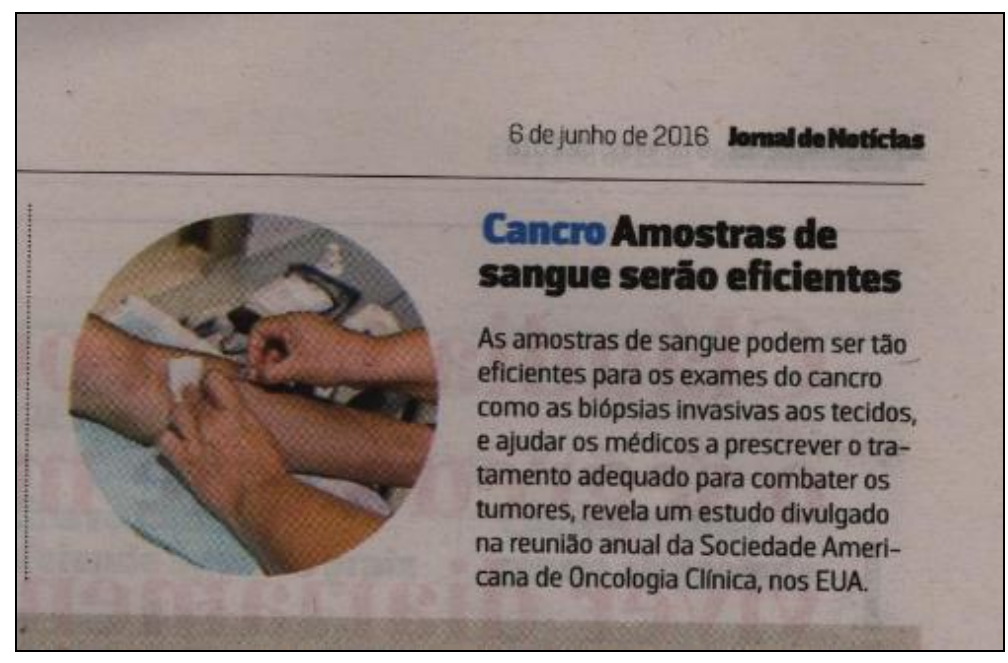

Texto 4: "Amostras de sangue serão eficientes"

http://www.literaciacientifica.pt/pdf files/JN 0007 P 56.pdf

Avaliando diversos recursos linguísticos e textuais, como o título, o corpo do texto, a imagem, bem como a informação de caráter paratextual, depreende-se com facilidade que este texto tem como intenção comunicativa divulgar uma descoberta científica relativa à área da saúde, a saber a eficiência das amostras de sangue nos exames do cancro. Todavia, a configuração gráfica e o tamanho do texto (bloco textual único e pouco extenso) não possibilita a sua exata integração num género textual estabilizado.

\section{Organização do conteúdo temático das secções jornalísticas, das tags e do corpo do texto}

Os novos formatos tendem a banir as divisões clássicas e a promover a informação indexada por palavras-chave ou hashtags. Os textos, que seguem, são exemplos desta alteração na forma como o conhecimento é estruturado. No primeiro exemplo temos uma notícia que foi publicada na secção de economia, com uma etiqueta que enquadra o texto numa subsecção intitulada "inovação": uma empresa líder de mercado desenvolve técnicas/tecnologias dentro da sua área de atuação. Esta interpretação não pode ser dissociada de um contexto socioeconómico em que está integrada, nem do ângulo de entrada privilegiado para a leitura e para a interpretação da notícia, a saber o investimento em investigação feito no meio empresarial. Deste modo, a notícia valoriza a empresa enquanto líder no seu sector de atuação, relegando a divulgação científica (um novo método para analisar quimicamente o vinho) para segundo plano, como se pode observar abaixo: 


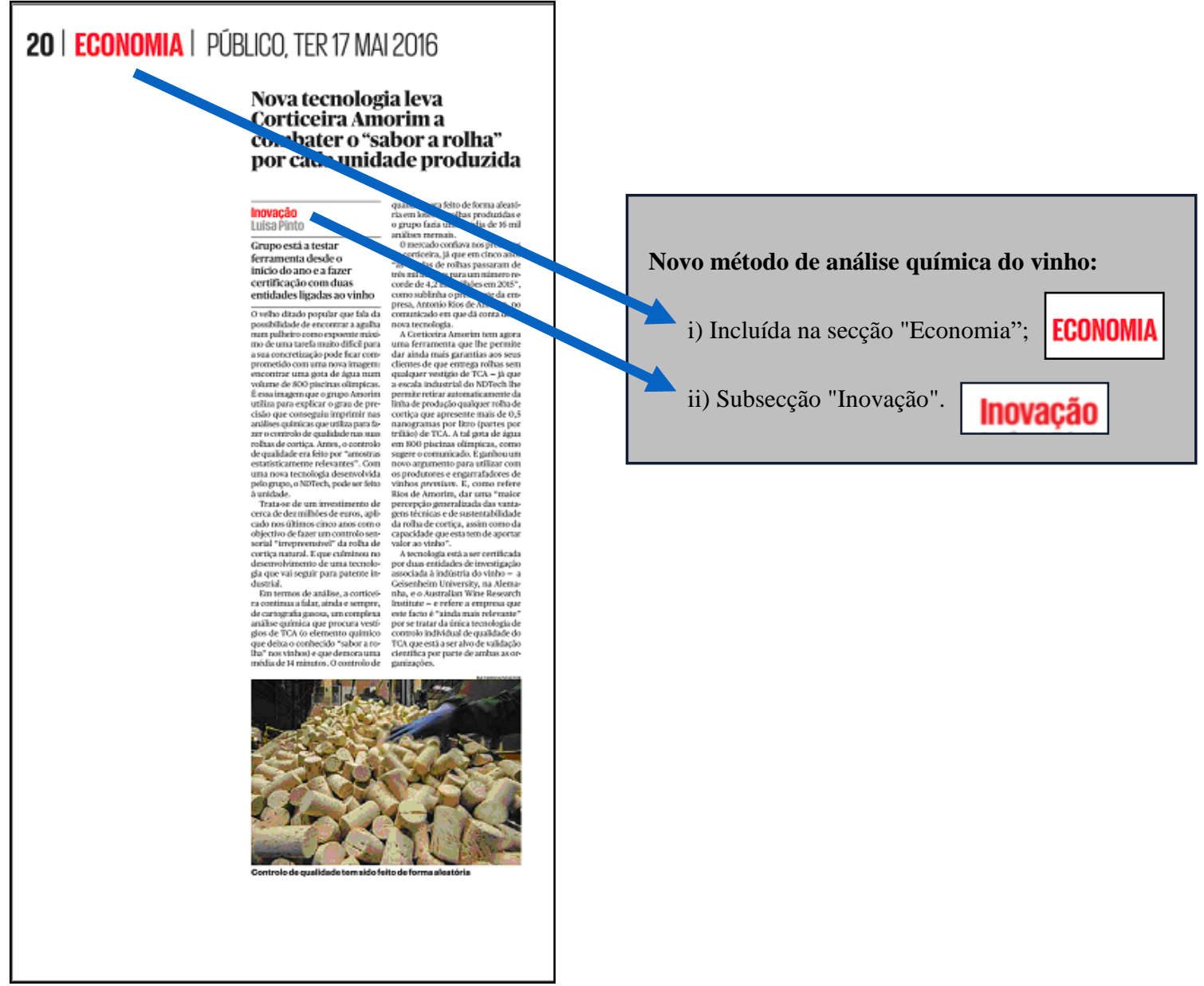

Figura 1. Relações entre o conteúdo temático e subsecções jornalísticas "Economia”, "Inovação"

O segundo texto em análise mostra como a mesma notícia pode ter tratamentos diferenciados, conforme o suporte de divulgação. Enquanto na edição impressa (que obriga a uma organização mais rígida do conteúdo) a notícia é publicada na secção "Economia", a edição digital da mesma notícia é integrada na secção "Tecnologia", privilegiando-se a adoção de palavras-chave/tópicos "transportes, Google, empresas, automóveis". São estes tópicos que irão indexar o texto, permitindo não só pesquisá-lo por qualquer uma destas palavras-chave, mas também agregá-lo a textos com tópicos semelhantes. Se, por um lado, isto permite quase instantaneamente reunir o produto de uma pesquisa, por outro, o resultado desta pesquisa estará mais suscetível ao "ruído" informativo ou, por outros termos, ao excesso de conteúdo, mas também à dispersão da informação, como veremos mais adiante (cf. Novas hierarquias do conhecimento). 


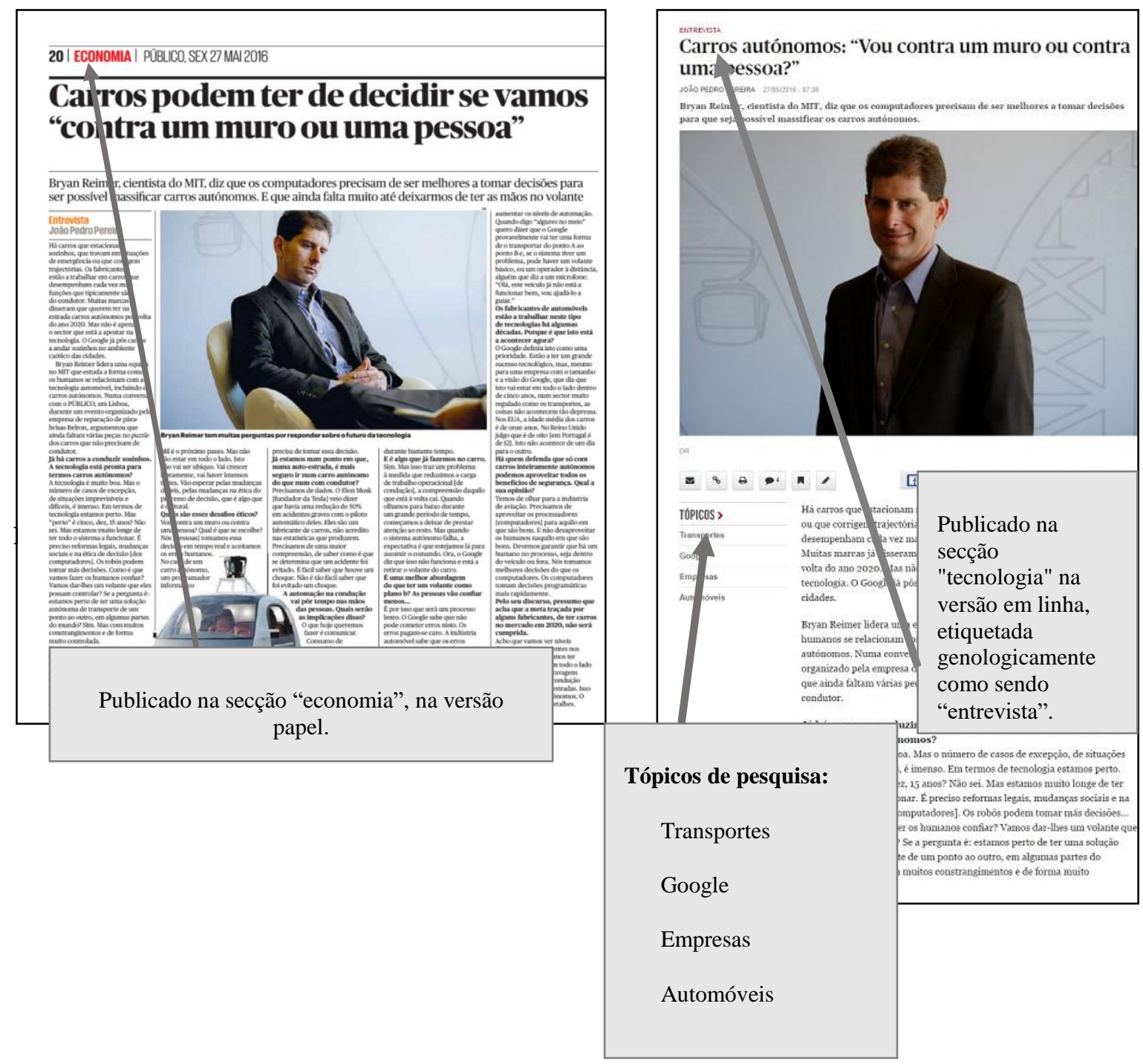

Figura 2. Relações entre o conteúdo temático, subsecções jornalísticas "Economia” e palavras-chave

A alteração de suporte tem implicações quer na organização textual e na composicionalidade - a disposição por colunas ou numa coluna única atestam o tipo de suporte - quer na construção do conhecimento, como será discutido na secção que segue. 


\section{Da transformação dos suportes textuais e suas implicações linguísticas}

O surgimento do codex enquanto suporte de escrita, além dos aspetos práticos e materiais (espaço ocupado, manuseamento, hierarquização da informação), permitiu organizar de forma mais racional o texto e construir a página enquanto espaço enunciativo. A passagem do pergaminho ao codex faz nascer psiquicamente a página, surgindo, desse modo, como um elo entre a prática da escrita e o texto. Assim, o enquadramento proporcionado pela página torna-se uma ferramenta (psíquica) e o dispositivo gráfico transforma-se numa unidade linguística e textual. Esta passagem vai permitir, a partir desse momento, a semantização do espaço gráfico. Na ligação entre o suporte e o texto, a grelha tipográfica vai possibilitar não só fragmentar o tempo e/ou o espaço da escrita em unidades regulares, como também irá dar resposta à tensão que se estabelece entre o conteúdo da página e o enquadramento em que este último tem lugar. $\mathrm{O}$ enquadramento gráfico do texto funciona, pois, como um elemento operatório que orienta a leitura e, por isso, ultrapassa a unidade física do documento. A assunção do enquadramento gráfico enquanto espaço de significação conduz-nos a uma reflexão sobre o conceito de enunciação editorial, tal como avançada por Goody (1977), segundo a qual a projeção gráfica permite a agenciação de significados num espaço bidimensional. Assim, a disposição dos signos linguísticos numa determinada superfície permite organizá-los e hierarquizá-los, numa relação de sentido. Uma das interrogações decorrentes desta interpretação é o modo como a disposição espacial dos signos pode fazer sentido. Para Harris (1993) a análise de um texto escrito tem de ter em conta as propriedades visuais do mesmo. Isto significa que existem determinados elementos que ocupam espaços específicos no enquadramento gráfico e que o leitor os identifica como unidades constitutivas do texto, sintetizadas pelo autor no Principe du Casier: "l'écriture tend naturellement à exiger ou à encourager une division du champ visuel selon les fonctions intégrationnelles pertinentes" (Goody, 1977: 229).

A abordagem integradora, referida por Goody, parte de dois princípios fundamentais: 1) as estruturas significativas estão sempre visíveis e 2) nenhuma análise das estruturas é possível sem considerar o seu contexto. A abordagem integradora consiste, por isso, em mostrar como um determinado enquadramento gráfico se organiza em função dos signos visíveis que contém. Um exemplo desta abordagem é o texto poético, em particular as formas clássicas, onde determinados traços da oralidade (o ritmo e a rima, por exemplo) são transpostos para uma organização específica e convencionada do enquadramento gráfico. $\mathrm{O}$ texto, enquanto objeto linguístico, ocupa um espaço que não é apenas o da linha de escrita (unidimensional) mas o do próprio suporte de escrita e que comporta outras dimensões. Atualmente, as produções textuais caracterizam-se pela heterogeneidade, sobretudo com a democratização do acesso a suportes digitais, que obrigaram a uma nova reflexão teórica sobre novos modos de enquadramento gráfico. Se, no passado, o papel era o suporte principal do texto, nas últimas décadas este tem competido diretamente com os suportes e formatos digitais. A folha, formato que deu origem ao codex e que permitiu construir o espaço enunciativo da página, deixou de ter os limites que o papel materialmente impunha à escrita e, por isso, qualquer reflexão sobre a enunciação editorial deve ter em consideração três conceitos: a escrita, a prática e o suporte. Se a escrita mantém, atualmente, as características que a definem, já o suporte de escrita não mantém o seu estatuto. De facto, a estabilidade conferida anteriormente, foi, atualmente, substituída pela efemeridade do suporte. Deste modo, é possível afirmar que o suporte (digital) é um lugar onde os signos se estabilizam a si próprios, na sua forma e na sua organização. Do mesmo modo, as práticas de escrita colocam a questão da uniformidade ou diversidade. Como afirmam Jeanneret e Souchier:

L'analyse des pratiques éditoriales n'est qu'une approche pour définir les changements médiatiques contemporains, parmi beaucoup d'autres possibles. Mais, dès lors qu'on choisit de penser cette réalité en termes éditoriaux, il devient indispensable d'aborder les objets et les pratiques qui leur sont liées à partir d'un point de vue particulier, celui de l'invention des formes écrites, de l'imposition de ces formes, de la 
façon dont elles se disséminent et, ce faisant, de la façon dont elles encadrent la circulation des textes eux-mêmes. (Jeanneret \& Souchier, 2005: 5).

A ideia de enunciação editorial (sem nos debruçarmos sobre as questões terminológicas que esta implica) permite falar de um "enunciado" emitido pelos atores durante um ato enunciativo (que pode ou não ser verbal) e que estes atos enunciativos determinam a existência do texto aos olhos dos leitores. Significa, pois, que a enunciação editorial não pode ser perspetivada apenas do ponto de vista discursivo, mas também pelas suas componentes semióticas, materiais e visuais do texto. Assim, a enunciação editorial pode ser apreendida como uma composição heterogénea e dinâmica que compreende aspetos como o suporte técnico e semiótico, linguagens, práticas profissionais e sociais, entre outros. Trata-se de uma questão pertinente e que se reveste de grande atualidade, uma vez que a ideia de texto se ampliou com a emergência da era digital. Entre outras questões, a passagem do texto enquanto objeto abstrato a um objeto empírico, sobrepondo a noção de texto e escrita, permitiu abordar o texto enquanto objeto complexo. Os novos formatos digitais colocam em questão esta análise, sobretudo se atendermos à distinção entre texto digital e texto digitalizado. $\mathrm{O}$ texto enquanto objeto físico adquiriu novas fronteiras com os formatos digitais, que é importante repensar. E esta questão pode ser tratada em vários níveis, não só na linguística do texto e do discurso, mas também em outras áreas, nomeadamente a linguística de corpus, em que a estabilização do suporte é dificultada na era digital, e pelas possibilidades que os meios interativos oferecem enquanto suporte textual. Não só a definição de página tem evoluído, como as fronteiras que, anteriormente, eram feitas pela disposição gráfica e pela folha se tornaram mais complexas (o uso do hipertexto, por exemplo). Deste modo, há uma necessidade premente de substituir o termo página (utilizado nos primórdios da internet) pelo termo ecrã enquanto espaço enunciativo.

$\mathrm{Na}$ linguística de corpus, a passagem da página ao ecrã coloca, igualmente, algumas questões importantes, e entre elas podemos destacar a estabilização do suporte e a delimitação de fronteiras do texto. A primeira questão, de ordem técnica, refere-se à necessidade que a linguística de corpus tem de ter acesso a um objeto material para ser utilizado. Neste sentido, têm-se desenvolvido vários trabalhos com o objetivo de replicar o enunciado original (sendo a Text Encoding Initiative a mais conhecida). Por outro lado, a segunda questão relaciona-se diretamente com a ausência de uma resposta satisfatória sobre os limites físicos do texto: se no passado o livro ou a biblioteca constituíam o espaço físico do texto, na internet (e mais ainda com o desenvolvimento da web 2.0 ou web semântica) essa delimitação física tem vindo a desaparecer. Um dos exemplos mais notórios é a utilização de hiperligações para a contextualização de um determinado assunto do texto, tal como se viu, nas palavras-chave, na figura 2.

\section{Novas hierarquias do conhecimento}

O segundo aspeto que a organização deste corpus evidenciou prende-se com a própria organização do corpus e, por extensão, do conhecimento. A disponibilização dos documentos implica a sua organização e a forma de a tornar acessível ao público. Para isso, é necessário indexar a informação (operação através da qual é feita uma descrição e identificação do documento pelo seu assunto) para que seja disponibilizada. Esta operação implica, num primeiro momento, a decisão quanto ao que é tratado no documento e, num segundo momento, o provável interesse que a decisão em causa tem para determinado grupo de utilizadores. Essa ação implica uma hierarquização da informação, onde seja possível estabelecer uma relação de hiperonímia/hiponímia do conhecimento, que está a desaparecer nos formatos digitais. Se nos primórdios da internet as restrições tecnológicas obrigaram à transposição do formato "livro" para a organização do conhecimento (menus, índices, secções) - não podemos esquecer que a terminologia digital conserva esses resquícios (uma "página" da internet) -, o desenvolvimento da tecnologia, sobretudo dos algoritmos de pesquisa, tornou esse formato obsoleto. Na verdade, passámos da mera leitura de informações, como sucedia 
nos anos 90 do século XX, para a uma intervenção direta nos conteúdos que estão disponíveis na rede, através de posts, comentários e outros tipos de escrita. Esta rede de "leitura/escrita" é designada de Web 2.0 e a sua emergência está diretamente relacionada com as chamadas "redes sociais digitais". Atualmente, assistimos ao crescimento das chamadas redes sociais semântico-lógicas ou Web 3.0 em que, além da ação de leitura/escrita, os utilizadores estabelecem relações de significado entre os diversos conteúdos de um ou vários sítios das redes globais. Estas relações, estabelecidas com o auxílio de ferramentas de interpretação (thesauri, nuvens de tags, redes interconcetuais, campos semânticos, entre outros) disponibilizam novas formas de processar a informação e o conhecimento:

[A Web 3.0] Entende-se como um novo estilo de receção, produção e partilha de informação, conhecimento e significado. Muitas vezes, a Web 3.0 é nomeada "Web semântica", na medida em que o seu principal objetivo é a construção de sítios e redes onde o seu próprio paradigma ou modelo de sentido e de conhecimento subjacente se encontra manifesto e/ou descrito, por vezes em pormenor.

Por outras palavras, no interior destes semantic web sites (ou sítios semânticos na Internet), a informação é organizada em torno de Ontologias, que se definem como modos de organização de significados, constituído, entre outros instrumentos, por conjuntos de relações semânticas e lógicas, estabelecidas entre os elementos ou pólos de informação. (Andrade, 2011)

Nos documentos recolhidos foi possível identificar vários exemplos deste conflito, sobretudo quando comparamos os textos em suporte papel e em suporte digital, uma vez que o suporte papel é obrigatoriamente mais conservador na indexação das notícias. Assim, o acesso a um determinado texto, na internet, pode ser feito através de tópicos de pesquisa, tornando obsoleto o acesso através das tradicionais páginas/secções, e tem implicações na forma como a informação é divulgada. Mostra, também, que a divulgação de ciência não é uma prática estabilizada.

\section{Notas conclusivas}

Como atesta o presente trabalho, a organização do corpus do projeto Promoção da Literacia Científica evidenciou vários aspetos importantes. O primeiro prende-se com a heterogeneidade, quer pela diversidade, quer pela natureza dos formatos textuais, utilizados no âmbito de uma mesma prática comunicativa, a literacia científica, difundida pelos meios jornalísticos escritos portugueses atuais: reportagem, entrevista, notícia, bem como formatos textuais sem etiquetagem genológica reconhecida e estabilizada. O segundo aspeto foca a necessidade de dar conta dos fenómenos de "transição" de uma organização de "página", enquanto réplica do formato papel para uma organização mais ramificada. Consequentemente, esse aspeto convoca um terceiro, correspondente à passagem de uma organização vertical e hierárquica (bidimensional) a uma organização horizontal e espacial (tridimensional) que se traduz na abolição de fronteiras nítidas dos conteúdos tematizados com consequências para a construção do conhecimento. A literacia, entendida como um conjunto de ferramentas de leitura/escrita que permitem a aprendizagem de conhecimentos, o desenvolvimento das potencialidades do indivíduo e a participação ativa na sociedade, ultrapassa as competências de compreensão e expressão da língua materna. Neste contexto, a promoção da literacia científica passa pelo desenvolvimento de ferramentas de leitura e de compreensão, para as quais a investigação em linguística (dos textos e dos discursos) e em didática do português tem um papel decisivo.

Em suma, este artigo visou uma melhor compreensão das relações entre corpus, géneros textuais, textos e suporte, através da questão da divulgação científica e contribuiu para a discussão sobre as novas relações entre as disciplinas científicas e o empírico, tendo em conta os documentos digitais e as alterações subjacentes aos novos formatos, tal como sublinhado por Rastier (2011: 12). 


\section{Referências}

Adam, J.-M. (1999) Linguistique textuelle. Des genres de discours aux textes. Paris: Éditions Nathan.

Andrade, P. (2011) Web 2.0, prolegómeno da Web 3.0?, in Revista de Comunicação e Linguagens, $\mathrm{n}^{\circ} 42$ «Genealogias da Web 2.0». Lisboa: Relógio d’Água.

Bronckart, J.-P. (1997) Activité langagière, textes et discours. Pour un interactionnisme discursif. Lausanne: Delachaux et Niestlé.

Coutinho, M. A. \& Miranda, F. (2009) To describe textual genres: problems and strategies. In Bazerman, Charles, Bonini, Adair, and Figueiredo, Débora, (eds.) Genre in a Changing World, ed. 1 - 528. Fort Collins, Colorado: The WAC Clearinghouse and Parlor Press, pp. 35-55.

Genette, G. (1987) Seuils. Paris: Éditions du Seuil.

Gonçalves, M., Jorge, N., Ribeiros, I., Cunha, I., Luís, M. R., \& Coutinho, A. (2018) Trabalhar com textos de divulgação da ciência na disciplina de Português. In Gonçalves, M. \& Jorge, N. (org.) (2018). Literacia científica na escola. NOVA FCSH- CLUNL. Disponível em http://www.literaciacientifica.pt/publicacoes ISBN 978-989-54081.

Gonçalves, M. \& Jorge, N. (org). (2018) A literacia científica na escola. In www.literaciacientifica.pt/publicaçoes ISBN 978-989-54081.

Gonçalves, M., Jorge, N., Ribeiros, I., Luís, R., Coutinho, M. A. (2017) Divulgação da ciência na aula de Português. In Atas do $12 .^{\circ}$ Encontro Nacional da Associação Portuguesa de Professores de Português (ENAPP). ISBN:978-989-96117-4-0.

Gonçalves, M. \&, Jorge, N. (aceite) Potencialidades do plano de texto no ensino da língua materna. In Atas do II Encontro APL/ESE.

Gonçalves, M. \& Rosa, R. (submetido) O suporte digital na leitura e compreensão textual. In Atas do IV Congresso Internacional Pelos Mares da Língua Portuguesa.

Goody, J. (1977) The Domestication of the Savage Mind. Oxford University Press.

Harris, R. (1993) La sémiologie de l'écriture. Paris: CNRS Editions.

Jeanneret, Y., \& Souchier, E. (2005). L'énonciation éditoriale dans les écrits d'écran. Communication et Langages, (145), pp. 3-15.

Jorge, N. (2014) O género memórias. Análise linguística e perspetiva didática. Tese de doutoramento em Linguística, NOVA | FCSH (https://run.unl.pt/bitstream/10362/12524/1/NJorge Tese.pdf)

Leal, A. (2018) Multimodalidade e Argumentação no Género Reportagem. Diacrítica, 32(1), pp. $25-41$. https://doi.org/10.21814/diacritica.133

Volochinov, V.N. (1977) Le marxisme et la philosophie du langage. Paris : Minuit.

Rastier, F. (2001) Arts et Sciences du Texte. Paris : P.U.F.

Rastier, F. (2011) La Mesure et le Grain: Sémantique de corpus. Paris: Honoré Champion. 